\title{
Azocontaining polymers, in situ immobilized on the silica gel surface
}

\author{
Y. Polonska ${ }^{a}$, E. Yanovska ${ }^{a}$, I. Savchenko ${ }^{a}$, L. Ol'khovik ${ }^{a}$, D. Sternik ${ }^{\text {, }}$, and \\ O. Kychkyruk \\ ${ }^{a}$ Taras National Shevchenko University of Kyiv,60, Volodymyrska str., 01601Kyiv, Ukraine; ${ }^{\mathrm{b}}$ Maria Curie- \\ Skłodowska University, Maria Curie-Sklodowska Sq., 20-031Lublin, Poland; 'Ivan Franko Zhytomyr State \\ University, 42 Pushkina Str., 10008Zhytomyr, Ukraine
}

\begin{abstract}
By mean of heterophase polymerization on the silica gel surface has been made in situ immobilization of poly[4-methacroyloxy-(4'-carboxy)-azobenzene], poly[4-methacroyloxy-(4'-carboxy-3-chloro)-azobenzene] and poly[(4-methacroyloxy-(4'-carboxy-2'-nitro)azobenzene has been received new organic-mineral composite materials. As a result of a detailed study of the sorption properties of the synthesized materials, it was found that the best sorption properties for toxic metal ions are silica gel, in situ modified by poly[(4-methacroyloxy-(4'-carboxy-2'-nitro)azobenzene. In particular, this composite showed a high sorption capacity for the ions $\mathrm{Pb}$ (II) and $\mathrm{Cu}$ (II).
\end{abstract}

\section{KEYWORDS}

adsorption; poly[4methacroyloxy-(4'-carboxy)azobenzene]; poly[4methacroyloxy-(4'-carboxy3-chloro)-azobenzene]; poly[(4-methacroyloxy-(4'carboxy-2'-nitro)azobenzene; composite; in situ immobilization; heavy metals; silica

\section{Introduction}

Modern cleaning technology of industrial wastewater brings in a focus some requirements in development of new adsorbents, foremost their multifunctionality including simultaneous extraction cationic and anionic forms of toxic metals from solutions, nontoxicity, simplicity and relatively low cost in large-scale synthesis. Inorganic/inorganic, organic/inorganic or bio/inorganic hybrid compounds constitute a class of materials of considerable interest most of all because they might combine within a single edifice the properties of their constituents [1-3]. The controlled assembly of the two components at a nanoscale level is suitable for providing new multifunctional systems in which each sub-network might exhibit its own properties or might contribute to new physical phenomena and novel applications. There is considerable interest in the synthesis and characterization of azobenzene-containing polymers because of their potential applications in optoelectronics, as stable paints, analytical reagents, phosphors, etc. [4-6]. Both monomeric and polymeric azo compounds are widely known for their interesting complex-forming properties $[7,8]$.

The modification of the surface of porous inorganic materials by nitrogen-containing polymers allows to obtain sorbents for removing toxic metals from the waste water due to their complexation with nitrogen atoms of immobilized polymer [9-11]. One of the promising ways of creating organo-mineral composite materials with valuable sorption properties is polymerization or in situ immobilization, which consists in the direct 
formation of an immobilized polymeric layer in the presence of particles of inorganic matrix [12-14].

The purpose of this work is to compare the sorption properties of the ions $\mathrm{Pb}$ (II), Cd (II), Mn (II), Cu (II) and Fe (III) of silica gels, in situ immobilized by poly[4-methacroyloxy-(4'-carboxy)-azobenzene], poly[4-methacroyloxy-(4'-carboxy-3-chloro)-azobenzene $]$ and poly[(4-methacroyloxy-(4'-carboxy-2'-nitro)azobenzene .

\section{Experimental}

\subsection{Synthesis}

For the study, the silica gel produced by Merck (fraction of particles with a diameter of 0.1-0.2 mm), whose surface parameters are given in Table 1, were used.

The polymerization of the corresponding azobenzene-containing monomers was carried out on the surface of silica gel in an inert atmosphere created by purging argon in the presence of 2,2'-azo-bis(isobutyronitrile) as the initiator, in tetrahydrofuran at $60-62^{\circ} \mathrm{C}$ for $4-6$ hours in a silicon bath similarly [14].

\subsection{Characterization methods}

IR spectra of the original and modified silica gel were recorded using an infrared spectrophotometer "Spectrum BX" (Perkin Elmer, Germany) in the range $500-4000 \mathrm{~cm}^{-1}$ in tablets $\mathrm{KBr}$.

The amount of immobilized polymer on the silica gel surface was evaluated by thermogravimetric analysis results obtained with simultaneous TG/DTA analyzer Shimadzu DTG- $60 \mathrm{H}$ (Japan) with computer registration of data in the $15-1000^{\circ} \mathrm{C}$ temperature range. The heating rate of samples is $10^{\circ} \mathrm{C} / \mathrm{min}$.

Thermal analysis was carried out on a STA 449 Jupiter F1, Netzsch (Germany) with mass spectroscopy console QMS 403C Aeölos (Germany)

The values of the surface area, average volume and average pore diameter were calculated from the data of low temperature nitrogen adsorption/desorption isotherms using the "ASAP 2420 V1.01" (Micromeritics, USA) sorbetometric software. Before measurements, samples were degassed at $60^{\circ} \mathrm{C}$ for 24 hours.

The morphology of the surface of silica gel before and after modification by polymer was investigated by scanning electron microscopy using the electron microscope "SEM LEO 1430 VP" (Carl Zeiss, Germany).

Sorption characteristics of the synthesized material with respect to $\mathrm{Cu}$ (II), Cd (II), $\mathrm{Pb}$ (II) and $\mathrm{Fe}$ (III) ions were studied in static mode. At the same time, $0.1 \mathrm{~g}$ of the composite was contacted with $25-100 \mathrm{ml}$ of working solutions of nitrates of the

Table 1. Characteristics of the surface of silica gel and synthesized composites.

\begin{tabular}{|c|c|c|c|c|c|}
\hline \multirow[b]{2}{*}{ Sample } & \multicolumn{3}{|c|}{ Surface area, $\mathrm{m}^{2} / \mathrm{g}$} & \multirow[b]{2}{*}{ Average pore volume $\mathrm{cm}^{3} / \mathrm{g}$} & \multirow[b]{2}{*}{ Average pore size, $\mathrm{nm}$} \\
\hline & $\mathrm{P} / \mathrm{P}_{0}$ & BET & Langmuir & & \\
\hline Silica gel & 447.00 & 463.53 & 686.91 & 0.686 & 5.92 \\
\hline Composite 1 & 385.8 & 402.1 & 599.8 & 0.607 & 6.04 \\
\hline Composite 2 & 309.3 & 326.5 & 493.5 & 0.505 & 6.19 \\
\hline Composite 3 & 341.0 & 358.1 & 539.08 & 0.570 & 6.36 \\
\hline
\end{tabular}


corresponding metals. The interaction took place for 10, 30, 60, 90 minutes and day with mechanical shaking. The equilibrium concentration of metal ions was fixed by the atomic absorption method.

The working solutions of the nitrates of the selected metals for the study of the sorption properties of the modified silica gel were prepared from the sets of "standard samples of solutions" of these salts (produced by AV Bogatsky, Odessa) on the background of $1 \mathrm{M} \mathrm{HNO}_{3}$ at concentrations of 1 and $10 \mathrm{mg} / \mathrm{ml}$.

To create a medium with $\mathrm{pH} 4$, a phthalate buffer solution was used from a set of "Standard buffer solutions" (DSTU 8.135: 2009, manufacturer of OJSC "Kiev plant of RIAP"). pH 2.8 was made by adding $0.1 \mathrm{M}$ acetic acid, which was prepared from fixanal. The exact $\mathrm{pH}$ of the working solutions was determined using the $\mathrm{pH}$ meter "HANNA TESTER WP" (Hanna instrument, China).

The adsorption capacity $(A)$ was calculated using the formula:

$$
A=\left(c_{\mathrm{o}}-[M]\right) V / m
$$

where $c_{o}$ - initial molar metal concentration, $[M]$ - balanced molar metal concentration, $V$ - is the volume of the working solution, $m$ - is mass of the adsorbent (g).

The adsorption rate $(\mathrm{R})$ was calculated according to the equation:

$$
R=\left(m_{a d s} / m_{\mathrm{o}}\right) \cdot 100 \%=\left(m_{\mathrm{o}}-[m]\right) / m_{\mathrm{o}} \cdot 100
$$

where $m_{o}$ - is mass of metal in the starting solution $(\mathrm{mkg}), m_{a d s}-$ mass of adsorbed metal, $[m]$ - is mass of the metal at equilibrium after the adsorption, which was found $[m]=C \cdot V$, where $C-$ is concentration of the metal at equilibrium $(\mathrm{mrg} / \mathrm{ml})$ and $V-$ is the volume of the solution at equilibrium $(\mathrm{ml})$.

The balanced metal ions concentration was defined by atom-absorption method. Atom-absorption measuring was made by flame atom-absorption spectrophotometer "Saturn" (Ukraine) in flame solution "air - propane - butane". The wavelengths were: for cuprum - $324.7 \mathrm{~nm}$, cadmium - $228.8 \mathrm{~nm}$, plumbum - $283.3 \mathrm{~nm}$, ferum - $248.3 \mathrm{~nm}$, and the width of the crack of $0.58 \mathrm{~cm}$. The balanced concentrations calculations in solution were made by comparing method of their lines intensity in the standard solutions intensity spectrum. Standard solutions were prepared with metal concentrations of $0.1-1.5 \mu \mathrm{g} / \mathrm{ml}$.

\section{Results and discussion}

The generalized scheme of in situ immobilization of monomers on the silica gel surface is shown in Figure 1.

The fact of polymer immobilization has been confirmed by IR spectroscopic method. Syntesized composite silica gel and monomer IR spectra comparing analyse testifies there are absorption bands from 3500 to $1200 \mathrm{~cm}^{-1}$, unlike the output of the matrix, which can be interpreted as follows [14-16]:absorption bands at $1385-1400 \mathrm{~cm}^{-1}$, there is $v(\mathrm{~N}=\mathrm{N})$ stretching vibrations, which are typical for nitrogen compounds;

- absorption bands from 2860 to $3070 \mathrm{~cm}^{-1}$ can be refered the $v(\mathrm{C}-\mathrm{H})$ to stretching vibrations of the polymer hybridized carbon link. Their presence at the composite spectra 


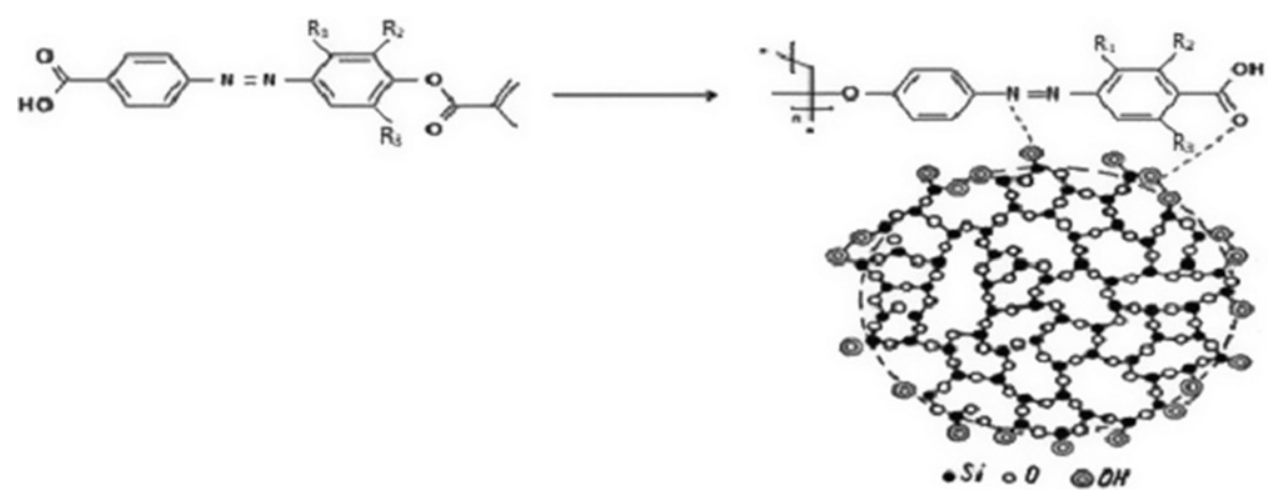

Figure 1. The scheme of in situ polymerization of azomonomers.**In the scheme of in situ polymerization of 4-methacroyloxy- (4'-carboxy) -azobenzene on the surface of silica gel $R_{1}, R_{2}, R_{3}=H$; in the scheme of in situ polymerization of 4-methacroyloxy- (4'-carboxy-2'-nitro) -azobenzene on the surface of silica gel $\mathrm{R}_{1}=\mathrm{H}, \mathrm{R}_{2}=\mathrm{NO}_{2}, \mathrm{R}_{3}=\mathrm{CH}_{3}$; In the scheme of in situ polymerization of 4-methacroyloxy(4'-carboxy-3-chloro) azobenzene on the surface of silica gel $R_{1}=C l, R_{2}, R_{3}=H$.

assures the fact of the polymerization reaction passing on the inorganic surface of the matrix.

- absorption bands at $3435-3460 \mathrm{~cm}^{-1}$ suits to the $v(\mathrm{O}-\mathrm{H})$ stretching vibrations of the carboxyl group.

In addition, in the IR spectrum of silicagel modified by poly [(4-methacryloxy-( $4^{\prime}$-carboxy-2'-nitro) azobenzene, an absorption band at $1660 \mathrm{~cm}^{-1}$ is available which can be attributed to valence asymmetric vibrations $v_{\text {as }}\left(\mathrm{NO}_{2}\right)$. Thus, the results of IR spectroscopy confirm the presence of a polymer on the surface of silica gel. In addition, the change of color of the silica gel to orange shows the immobilization of the azopolymer on the surface of the silica gel.

In order to determine the concentration of immobilized polymer, a thermogravimetric analysis of the synthesized composite and the original silica gel was performed.

By comparing the obtained thermograms, it has been found that the mass fraction of poly [4-methacroyloxy-( $4^{\prime}$-carboxy) -azobenzene] in the synthesized composite (composite 1$)$ is $10.61 \%$, a mass fraction of poly [4-methacroyloxy-( $4^{\prime}$ - carboxy -3-chloro) -azobenzene] in the synthesized composite (composite 2) is $13.33 \%$ and the mass fraction of poly [(4-methacroyloxy- $\left(4^{\prime}\right.$-carboxy- $2^{\prime}$-nitro $)$ azobenzene in the synthesized composite (composite 3) is $10.1 \%$.

To investigate the parameters of the surface of synthesized composites, the method of BET (low-temperature adsorption-desorption of nitrogen) was used. The resulting adsorption-desorption nitrogen isotherms for the original silica gel and the synthesized composites are similar and belong to the type IV isoterm according to the classification of IUPAC [17]. This suggests that the structure of the surface of silica gel as a result of fixing the selected polymers is unchanged practically.

The calculated by computer processing of nitrogen adsorption-desorption isotherms parameters of the surface of the synthesized composites are shown in Table 1. 


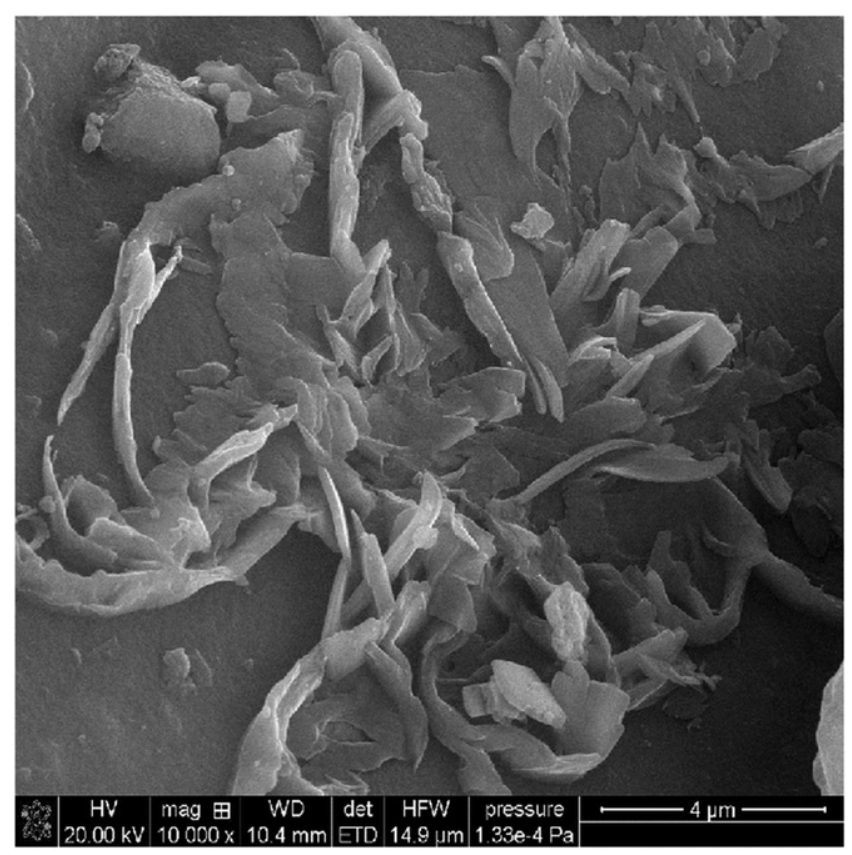

Figure 2. CEM photo of the surface of the composite 2 at an increase of 10000 times.

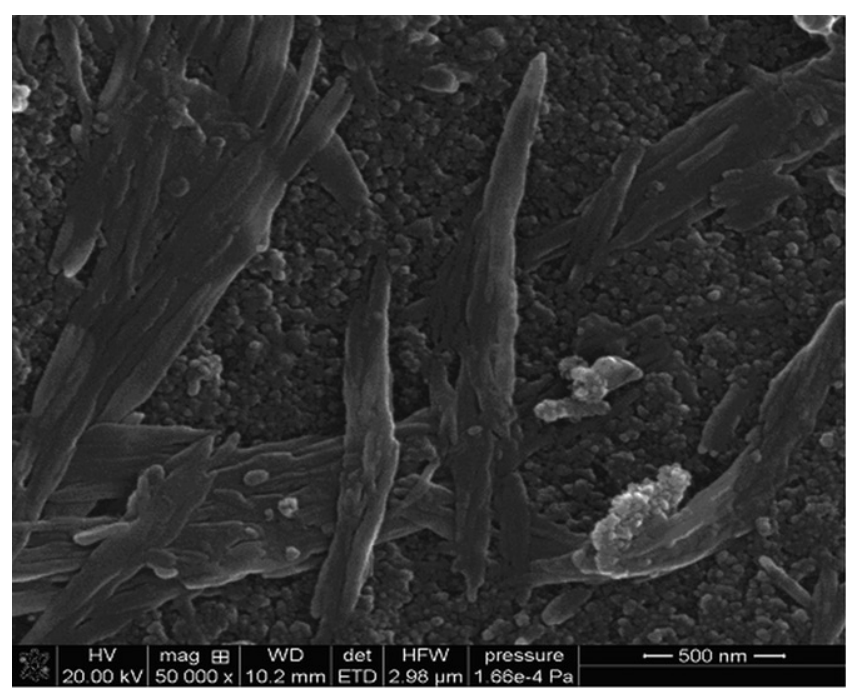

Figure 3. CEM photo of the surface of the composite 1 at an increase of 100000 times.

The obtained data testify that after immobilization of azopolymers the porosity of the surface of silica gel decreases insignificantly, and the average diameter of pores increases insignificantly.

Changes in the surface morphology of silica gel after modification by azopolymers were followed by scanning electron microscopy (CEM). The CEM-photos of modified silica gel are shown in Figures 2-4. 

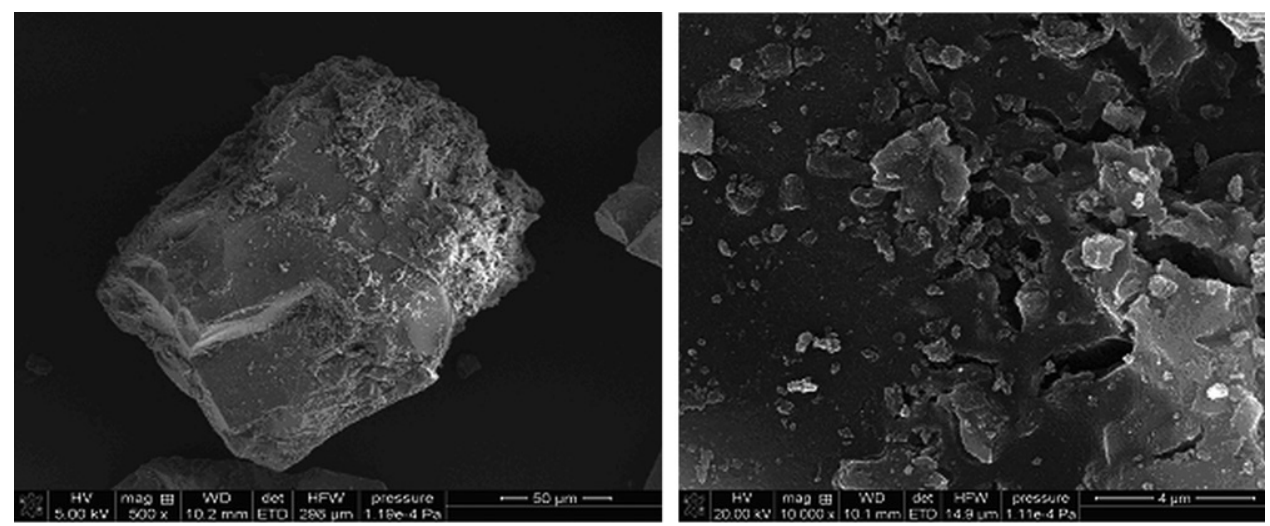

Figure 4. CEM image of composite 3 surface a) increase by 500 times, b) increase by 10000 times.

It is seen from photos 2 and 3 that on the surface of composites 1 and 2, polymers are arranged in the form of linear macromolecules. Immobilized polymers on a solid surface are in expanded state and their azo groups are sterically maximally available for participation in complexation. On the surface of the silica gel composite 3, the immobilized polymer formed a thin polymer layer (Figure $4 \mathrm{~b}$ ), similar to that described in [18]. It covers almost half of each particle of silica gel (Figure 4a).

Consequently, based on the results of computer processing of data, the isoterms of adsorption-desorption of nitrogen by the BET method and the analysis of CEM-photo revealed that all azo-containing polymers on the surface of the silica gel are distributed evenly in the form of a thin film or fibers. Their complexing centers are as accessible as possible to metal ions, which is the result of the chosen method of polymerization modification of the surface of silica gel.

Taking into account the close values of mass of immobilized polymers in the composition of synthesized composites, it can be argued that the sorption properties of synthesized composites for selected metal ions should differ mainly in the chemical nature of immobilized azopolymers. That is, the sorption properties of the synthesized composites for the selected metal ions should be determined by the ability of immobilized polymers to act as a ligand in the process of complexation with selected metals.

The synthesized composites should detect the sorption ability of ions of transition metals due to participation in the processes of complexation of nitrogen atoms of azo groups, atoms of oxygen of carboxyl groups, and in the case of composite 3 - also due to nitrogen atoms of nitro groups of immobilized polymers. To confirm these considerations, we investigated the sorption of $\mathrm{Cu}$ (II) and Fe (III) ions, which have high affinity for nitrogen-containing ligands [19]. Also, sorption of ions of toxic metals such as Cd (II) and $\mathrm{Pb}$ (II), which form complexes with oxygen atoms predominantly, was studied [19].

Investigation of the sorption capacity of the synthesized composite for these metal ions included:

- determination of the optimal $\mathrm{pH}$ range of the sorption medium; 
- establishing the required contact time of phases to achieve the sorption equilibrium in the static mode;

- construction of isotherms of sorption of each of the investigated metal ions on the surface of the synthesized composite;

- determination of sorption capacity for each of the investigated metal ions and comparison with the original silica gel.

In the previous experimental studies, it was found that in the alkaline medium, this immobilized polymer is partially washed away from the surface of silica gel, so the study of the sorption properties of the synthesized composite was carried out in an acidic and neutral medium only.

At the same time, in the initial solutions of the investigated metals aqua, chloride, acetate or phthalate coordination spheres were formed respectively. In the process of sorption such complexes interacted with the molecules of immobilized polymer with the formation on solid surfaces of multi-ligand complexes.

The synthesized composite exhibits the best sorption properties of the micro quantities of the selected ions in the aqueous medium (without the addition of any buffer solutions),

The quantitative sorption of the micro- quantities of $\mathrm{Pb}$ (II) ions on the surface of composites 1 and 3, quantitative sorption of micro-quantities of Fe (III) ions on the composite surface 1 was observed from the aqueous solutions of the selected metal nitrates. The quantitative sorption of any of the ions studied was not fixed on the surface of the composite 2 . This composite maximally removes ions of ferrum (III) in the acetate complexes (at $\mathrm{pH} 2.8$ ) and aqua complexes at a level of $73 \%$. It was found that the micro- quantities of $\mathrm{Cu}$ (II) ions is removed from the surface of all synthesized composites by $70-80 \%$ in an aqueous medium.

It should be noted that none of the composites showed sorption activity on the ions of Cd (II) and therefore, more detailed studies of the sorption of these ions on the surface of synthesized composites were not carried out.

Investigation of the dependence of the degree of sorption of $\mathrm{Cu}$ (II), $\mathrm{Pb}$ (II) and $\mathrm{Fe}$ (III) ions on the surface of synthesized composites from static contact time showed that the quantitative sorption of $\mathrm{Pb}$ (II) ions on the composite surface 3 occurs during the first minutes of contact. Quantitative sorption of ions $\mathrm{Pb}$ (II) on the surface of composite 1 is achieved within one hour of contact, and Fe (III) ions - during the day only.

In order to determine the values of the sorption capacity of the modified silica gel for the selected transition metal ions, their isotherms of sorption were constructed. All of the obtained isotherms belong to the $2 \mathrm{~L}$-species. The obtained isotherms allow to calculate the sorption capacity of the synthesized composites. The comparison of the sorption

Table 2. The comparison of sorption capacities for ions $\mathrm{Cu}$ (II), $\mathrm{Pb}$ (II) and Fe (III), original silica gel and synthesized composites.

\begin{tabular}{|c|c|c|c|c|c|c|c|c|}
\hline \multirow[b]{3}{*}{ Ion } & \multicolumn{8}{|c|}{ Sorption capacity } \\
\hline & \multicolumn{2}{|c|}{ Original silica gel } & \multicolumn{2}{|c|}{ Composite1 } & \multicolumn{2}{|c|}{ Composite 2} & \multicolumn{2}{|c|}{ Composite 3} \\
\hline & $\mathrm{mmol} / \mathrm{g}$ & $\mathrm{mg} / \mathrm{g}$ & $\mathrm{mmol} / \mathrm{g}$ & $\mathrm{mg} / \mathrm{g}$ & $\mathrm{mmol} / \mathrm{g}$ & $\mathrm{mg} / \mathrm{g}$ & $\mathrm{mmol} / \mathrm{g}$ & $\mathrm{mg} / \mathrm{g}$ \\
\hline$\overline{\mathrm{Fe}(\mathrm{iii})}$ & 0.008 & 0.49 & 0.016 & 0.89 & 0.016 & 0.89 & 0.016 & 0.89 \\
\hline $\mathrm{Pb}(\mathrm{ii})$ & 0.002 & 0.41 & 0.005 & 1.03 & 0.007 & 1.45 & 0.010 & 2.13 \\
\hline $\mathrm{Cu}(\mathrm{ii})$ & 0.006 & 0.38 & 0.012 & 0.77 & 0.009 & 0.58 & 0.086 & 5.50 \\
\hline
\end{tabular}


capacitance values of the synthesized composites with respect to $\mathrm{Cu}$ (II), $\mathrm{Pb}$ (II) and $\mathrm{Fe}$ (III), and the original silica gel is given in Table 2.

As follows from Table 2, the sorption properties of all synthesized composites for Fe (III) ions in the aqueous medium are practically the same and their sorption capacity is 2 times greater only than that for the original silica gel. In the case of the $\mathrm{Pb}$ (II) and $\mathrm{Cu}$ (II) ions, the highest sorption capacity was found in silicagel, modified of poly [(4methacroyloxy-( $4^{\prime}$-carboxy-2'-nitro) azobenzene (composite 3$)$, sorption capacity for $\mathrm{Pb}$ ions (II) is $0.01 \mathrm{mmol} / \mathrm{g}$, and for $\mathrm{Cu}$ (II) ions $-0.086 \mathrm{mmol} / \mathrm{g}$, which is significant for complex-forming sorbents [20]. This is the result of the introduction of the nitro group into the azopolymer, which was an additional ligand in the processes of complexation on the solid surface of the composite.

\section{Conclusions}

By mean of heterophase polimerization on the silica gel surface has been made in situ immobilization of poly[4-methacroyloxy-(4'-carboxy)-azobenzene], poly[4-methacroyloxy-(4'-carboxy-3-chloro)-azobenzene $]$ and poly[(4-methacroyloxy-(4'-carboxy-2'nitro)azobenzene new organic-mineral composite materials has been received.

The fact of immobilization of polymers on the surface of silica gel was confirmed by IR spectroscopy. Through thermogravimetric analysis, it was found that the mass $f$ of immobilized polymers in the synthesized composites are close to magnitude and are $10.61 \%$ for poly [4-methacroyloxy- $\left(4^{\prime}\right.$-carboxy) -azobenzene] for poly [4-methacroyloxy$4^{\prime}$-carboxy-3-chloro) -azobenzene] - $13.33 \%$ and for poly [(4-methacroyloxy-(4'-carboxy-2'-nitro) azobenzene - $10.1 \%$.

The analysis of CEM-photo revealed that all azo-containing polymers on the surface of the silica gel are distributed evenly in the form of a thin film or fibers. Their complexing centers are as accessible as possible to metal ions, which is the result of the chosen method of polymerization modification of the surface of silica gel.

As a result of studies on the sorption ability of synthesized composites for $\mathrm{Cu}$ (II), $\mathrm{Cd}$ (II), $\mathrm{Pb}$ (II) and Fe (III) ions, it was recorded that they exhibit the best sorption properties of the micro-quantities of the selected ions in a neutral aqueous medium without the addition of buffer solutions.

It has been found that the sorption properties of all synthesized composites for $\mathrm{Fe}$ (III) ions in the aqueous medium are practically the same and their sorption capacity is only 2 times greater than that for the original silica gel The highest sorption ability for $\mathrm{Pb}$ (II) and $\mathrm{Cu}$ (II) ions was found in silicagel, modified by poly [(4-methacroyloxy-( $4^{\prime}-$ carboxy-2'-nitro) azobenzene. This is the result of the introduction of the nitro group into the azopolymer, which was an additional ligand in the processes of complexation on the solid surface of the composite.

\section{References}

[1] Laberty-Robert, C., Valle, K., Pereira, F., Sanchez, C. (2011). Chem. Soc. Rev., 40, 961.

[2] Nagarale, R. K., Shin, W., Singh, P. K. (2010). Polym. Chem., 1, 388.

[3] Peighambardoust, S.,J., Rowshanzamir, S., Amjadi, M. (2010). Int. J. Hydrog. Energy, 35, 9349. 
[4] Lin, L., Feng, Z., Yu, Q., et al. (2009). Mol. Cryst. Liq. Cryst., 508, 214.

[5] Kasyanyuk, D., Davidenko, N., Kurioz, Y., Savchenko, I., Reznikov Y. (2015). Optics Express, 23, N 20, 26660.

[6] Savchenko, I., Davidenko, N., Davidenko, I., Popenaka, A., Sinyugina, A. (2008). Mol. Cryst. Liq. Cryst., 497, 316.

[7] Savchenko I., Davidenko N., Davidenko I., Popenaka A., Syromyatnikov V. (2008). Mol. Cryst. Liq. Cryst., 485, 254.

[8] Abdallah, S. M. (2012). Arabian Journal of Chemistry, 5, 251.

[9] Yanovska, E. S., Tertykh, V. A.,. Kichkiruk, O. Y., Dadashev, A. D. (2007). Adsorption Science \& Technology, 1-2, 81.

[10] Dadashev, A. D.,. Tertykh, V. A., Yanovska, E. S., Yanova, K. V. (2016). American Journal of Analitical Chemistry, 7, 411.

[11] Budnyak, T. M., Tertykh, V. A., Yanovska, E. S., Kołodynska, D., Bartyzel, A. (2015). Adsorption Science \& Technology, 6-8, 645.

[12] Sapurina, I., Stejskal, J. (2008). Polymer International, 57, 295.

[13] Sowa, I., Pizoń, M., Świeboda, R., Kocjana, R., Zajdel, D. (2012). Sep. Sci. Technol., 8, 1194.

[14] Yanovska, E., Savchenko, I., Sternik, D., Kychkiruk, O., Ol'khovik, L., Buriachenko, I. (2017). Nanoscale Research Letters, 12, 313

[15] Smith, A. L. (1982). Applied IR spectroscopy, Moscow: World, (in Russian).

[16] Tarasevich, B. N. (2012). IR spectra of the basic classes of organic compounds. Reference materials. Moscow: MSU them. M.V. Lomonosov, (in Russian).

[17] Parfitt, G. D. (1986). Adsorption from solution at the solid liquid interface. M.: Mir.

[18] Ryabchenko, K. V., Yanovska, E. S., Tertykh, V. A., Kichkiruk, O. Y., Sternik, D. (2014). Adsorption ScienceぬTechnology, 32, 88.

[19] Skopenko, V. V., Savranskij, L. I. (2004). Coordination Chemistry. Kyiv: Lybid, (in Ukrainian).

[20] Zaitsev, V. N. (1997). Complexing silica: synthesis, structure of the graft layer and surface chemistry. Kharkov: Folio (in Ukrainian). 